\title{
CEREBRAL ANEURYSMS PRESENTING WITH VISUAL FIELD DEFECTS*
}

\author{
BY \\ J. F. CULLEN, W. M. HAINING, AND A. L. CROMBIE \\ University Department of Ophthalmology and Royal Infirmary, Edinburgh
}

\begin{abstract}
ANEURYSMS occur more frequently within the cranium than elsewhere in the body, and most -75 to 85 per cent. according to Walsh (1964) - are situated on the anterior part of the circle of Willis. In this region they are closely related to the primary visual pathways and motor nerves to the eye. Extra-ocular muscle palsies are well recognized by ophthalmologists as indicative of such lesions, particularly if accompanied by pain in and around the eye. Green, Hackett, and Schlezinger (1964), in their evaluation of oculomotor nerve paralysis, reported that almost 30 per cent. of all isolated third nerve palsies could be attributed to aneurysms. It is less well recognized that patients harbouring these abnormalities can present initially with signs of compression of the visual pathways, thus exhibiting sensory rather than the more common ophthalmoplegic or motor involvement. Such sensory defects have been reported by Dailey, Holloway, Murto, and Schlezinger (1964), as occurring alone in 12 per cent. of cases of verified cerebral aneurysm, and combined with motor nerve involvement in a further 10 per cent. Walsh (1964), in a series of 117 proven cases, recorded visual field defect due to aneurysm in 13 per cent.

This paper reports two cases of cerebral aneurysm presenting with signs of compression of the visual pathway. In one, sudden ipsilateral blindness was the presenting symptom and in the other, the ocular defect was on the side opposite to that on which the aneurysm originated.
\end{abstract}

\section{Case Reports}

Case 1.-A 45-year-old housewife was referred to the Eye Department on April 29, 1964, because during the previous night she had been wakened from sleep by severe pain in the left eye which then passed to her forehead and later to the occipital region. Next morning, she discovered that this eye was blind. Up to the time of this episode she had been in excellent health and denied having had any headache in the past.

Examination.-The left eye was blind with no light perception. The media were clear and the optic disc was normal; the retinal arterioles were narrowed but there was no retinal oedema. The right eye was entirely normal and the right visual field was full. The ocular movements were full. There was no tenderness in or around the eyes, nor was there any proptosis. Ophthalmodynamometry gave normal readings. It was thought at this time that the patient had sustained a vascular

* Received for publication February 26, 1965. 
accident involving the left optic nerve and observation was advised. Two weeks later she experienced a further severe frontal headache, vomited, felt some neck stiffness, and at this time noticed some blurring of the vision of the right eye. The right visual acuity was now reduced to $6 / 18$ and $\mathrm{N} 12$, the pupil reaction was somewhat impaired, and there was an almost complete temporal hemianopia (Fig. 1). The optic disc was normal. The only abnormality on neurological examination was conspicuous briskness of all tendon-jerks with an equivocal extensor plantar response on the right side, and absent abdominal reflexes. Blood pressure was 150/80; plain skull and chest radiographs showed no abnormality. A lumbar puncture showed a xanthochromic fluid with a few cells; the pressure was normal. A diagnosis of a leaking aneurysm was made and it was presumed that the aneurysm had expanded and bled on two occasions. The patient was transferred to the Department of Surgical Neurology, where pan-angiography was carried out via a right femoral artery catheter and a large anterior communicating aneurysm was demonstrated.

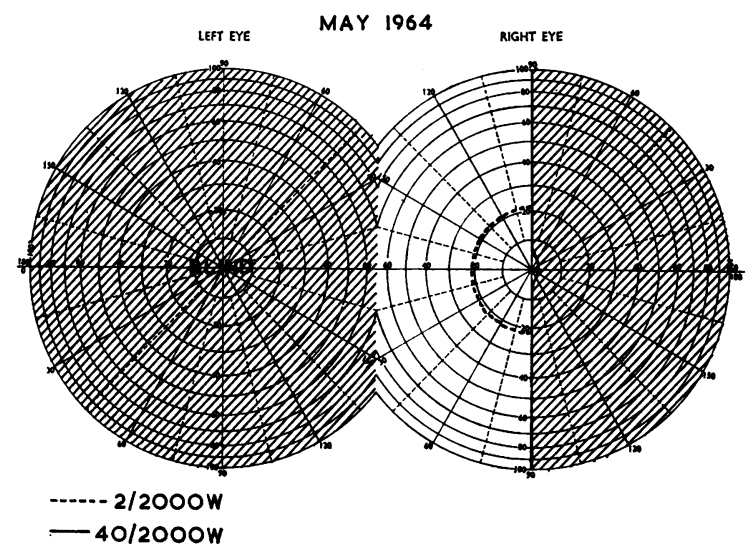

Fig. 1.-Case 1. Visual fields at second examination, May, 1964.

Operation.-On May 16, 1964, a bifrontal craniotomy was performed by Mr. J. F. Shaw. The aneurysm was exposed and it was confirmed that it lay deep to the optic nerve and chiasma; it was extremely large (much larger than indicated by the angiogram), the walls were arteriosclerotic, and the anterior cerebral arteries were adherent to its fundus. Both optic nerves coursed in an upward direction over the fundus, were adherent to it, and were displaced to the right. The left optic nerve was displaced to a considerably greater extent than the right one, and showed a degree of thinning and pallor. The aneurysm was followed backwards towards the region of the neck and, although this was not well seen, appeared to be broad and arising from an aggregation of both anterior cerebral arteries and the anterior communicating vessel. It was felt that the only treatment of safety in these circumstances was to wrap the exposed surfaces in muscle and this was undertaken uneventfully.

Result.-Post-operative recovery was satisfactory. It was now clear that the patient had an aneurysm which had already bled twice and was causing severe visual impairment and would, in all probability, bleed lethally or cause complete blindness in the near future. After further cerebral angiography (Fig. 2), it was therefore decided to make an attempt to excise the aneurysm under deep hypothermia using a cardiac by-pass and intermittent occlusion of the great vessels at the arch of the aorta. On June 8, 1964, a cardio-pulmonary by-pass was set up and cooling to $15^{\circ} \mathrm{C}$. performed without untoward event. The aneurysm was successfully excised, but cardiac arrest occurred as cranial haemostasis was being achieved after the patient had been taken off the by-pass and re-warmed. By re-opening the chest and performing cardiac massage the heart was started again, but the patient succumbed a few hours after operation. Post-mortem examination confirmed the operative findings. 


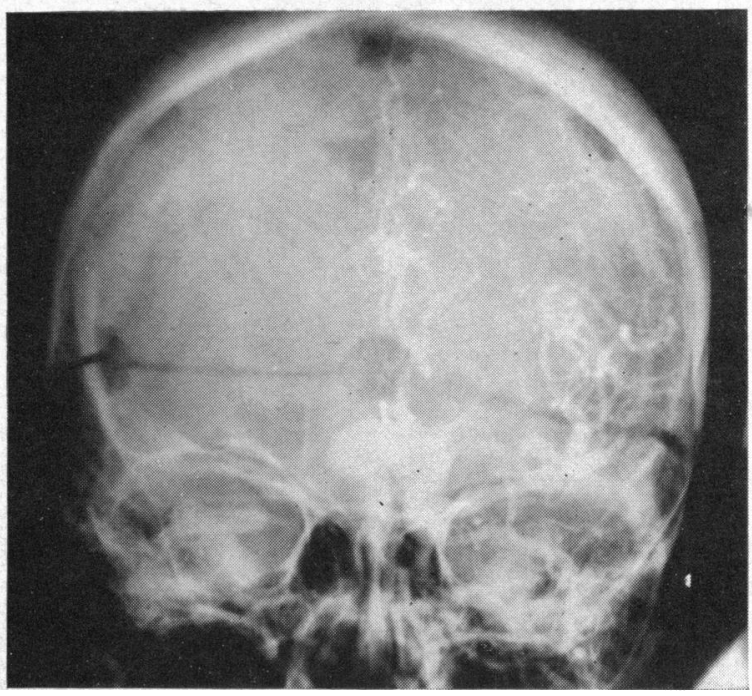

FIG. 2.-Case 1. Left carotid arteriogram showing the large multiloculated saccular aneurysm. The bifrontal osteoplastic craniotomy and some metallic clips used for haemostasis are also seen.

Comment.-Sudden unilateral blindness in a young or middle-aged person, especially if associated with pain, should suggest the possibility of an expanding or leaking aneurysm, even in the absence of involvement of the motor nerves to the eye. In the case reported, the progression of the field defect to that shown in Fig. 1 was pathognomonic of an expanding lesion at the anterior angle of the chiasma (Cullen, 1964).

Case 2. - A 58-year-old housewife was first seen in the Eye Department on December 6, 1963, with a history of severe left frontal headache associated with vomiting for three days, followed by severe retro-orbital pain on the left side. Over this period she also noticed some deterioration of vision in the left eye. The previous history was of intermittent bifrontal headaches for about two years, but there had been no fits or fainting attacks and no visual disturbance in the past.

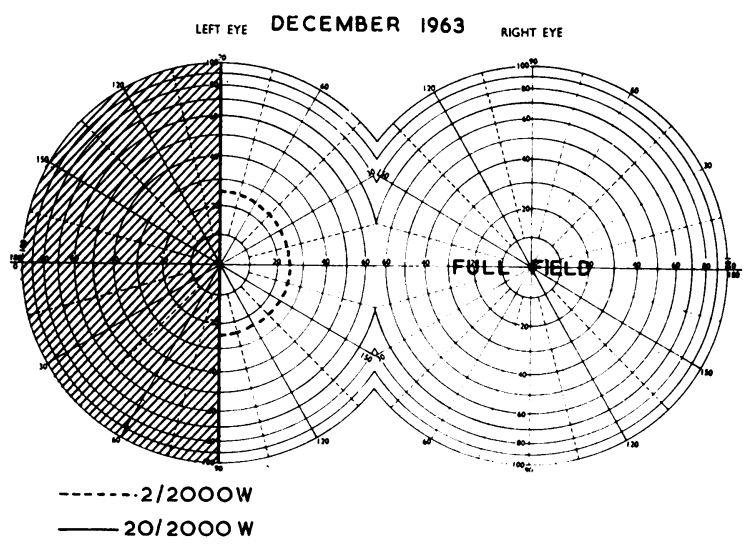

FIG. 3.-Case 2. Visual fields at first examination, December, 1963. 
Examination.-The visual acuity in the left eye was reduced to counting fingers. The pupil reaction was sluggish, and there was some pallor of the optic disc, the fundus being otherwise normal. There was a complete temporal hemianopic field defect in the left eye (Fig. 3). The right eye was entirely normal and the right visual field full. The ocular movements were full. Neck stiffness was also noted but no other neurological defects were detected. Plain radiography of the skull was normal, but examination of the cerebrospinal fluid showed blood-stained fluid with xanthochromia and, in view of thesefindings, the patient was transferred to the Department of Surgical Neurology as a probable case of spontaneous intracranial haemorrhage from an aneurysm in the left internal carotid system. Bilateral carotid arteriography was performed and showed a very large saccular aneurysm arising from the right internal carotid artery approximately $1 \frac{1}{2} \mathrm{~cm}$. proximal to the bifurcation (Fig. 4). It extended anteriorly and medially across the midline and measured $20 \mathrm{~mm} . \times 17 \mathrm{~mm} . \times 15 \mathrm{~mm}$.

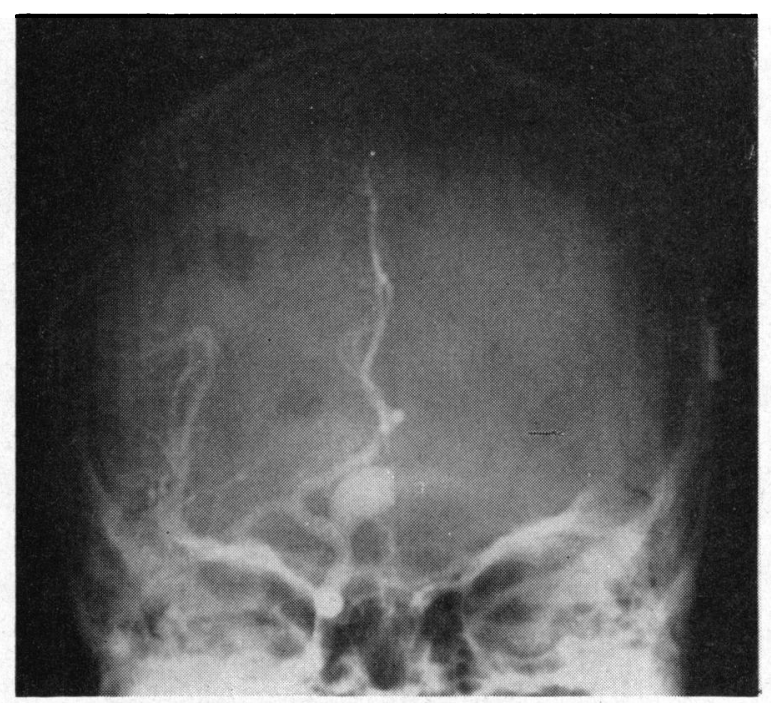

(a)

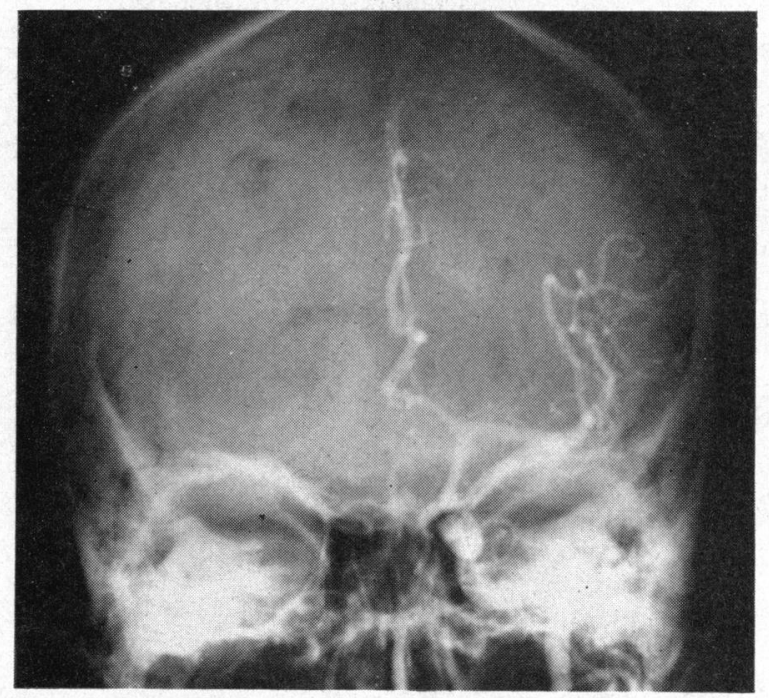

(b)

FIG. 4.-Case 2. Right (a) and Left (b) bilateral carotid arteriograms showing the aneurysm arising from the right internal carotid artery. 
Operation.-It was considered that it should be possible and surgically feasible to ligate the neck of this large aneurysm and, accordingly, a right frontal craniotomy was performed by Prof. F. J. Gillingham on December 11, 1963. The aneurysm was easily exposed and was found to extend across the midline and compress the left optic nerve. The neck, however, was posteriorly and medially placed, was very broad, and it was not possible to pass a ligature around it. In view of these findings the craniotomy was closed, the right internal and common carotid arteries exposed in the neck, and a slow occlusion Dott clamp was placed on the right common carotid. Four days later the clamp was fully occluded.

Result.-Post-operative recovery was slow and complicated by confusional state, left hemiparesis, chest infection, and, later, status epilepticus, thought to be due to a spreading thrombophlebitis, but eventually the patient's condition improved, she was able to be got out of bed, and began to walk reasonably well. By the end of January, 1964, she was making excellent progress and it was felt that she would make a normal recovery. However, on February 9, she suddenly collapsed and died within a few minutes.

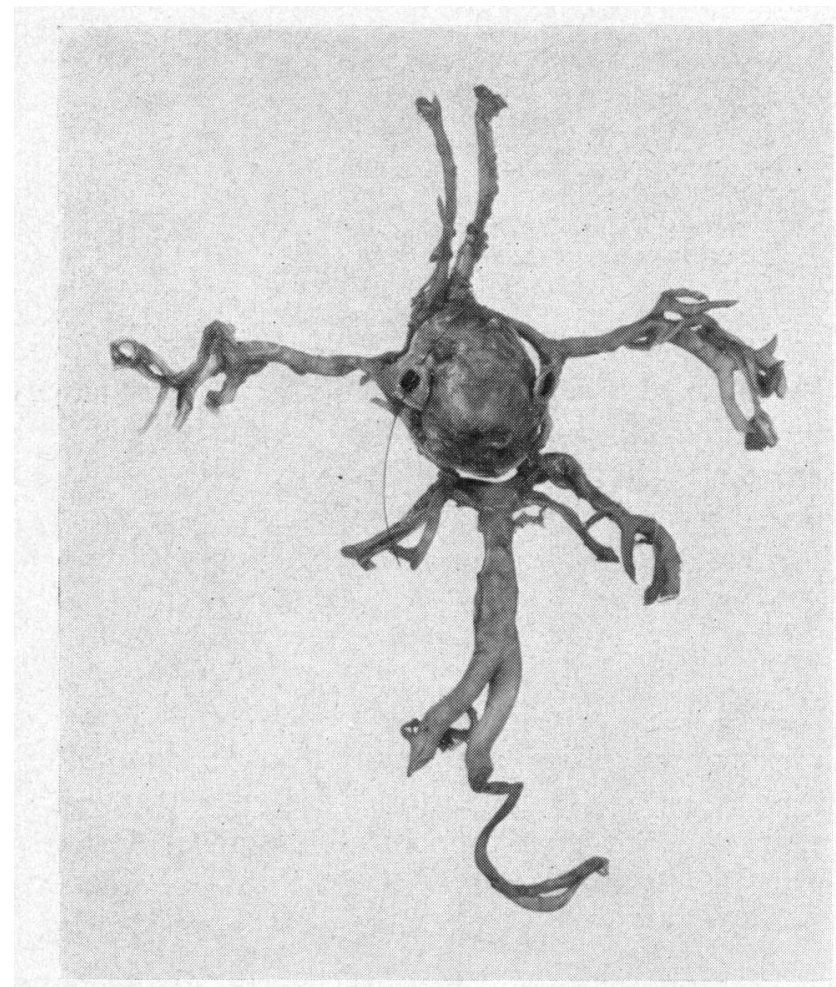

FIG. 5.-Case 2. Dissection of circle of Willis (seen from below) showing the aneurysm arising from the right internal carotid artery.

Post-mortem Examination.-Death was found to have been due to a massive embolus in the pulmonary artery. The circle of Willis was dissected out (Fig. 5) and the aneurysm, springing from the right internal carotid, located. The aneurysm was found to be deeply embedded in the floor of the third ventricle which it had invaginated (Fig. 6). The optic chiasma and nerves were stretched, flattened, and displaced upwards and backwards over the superior surface of the aneurysm. The aneurysm was filled with laminated thrombus undergoing organization. There was focal infarction in the right parietal lobe and corpus striatum. 


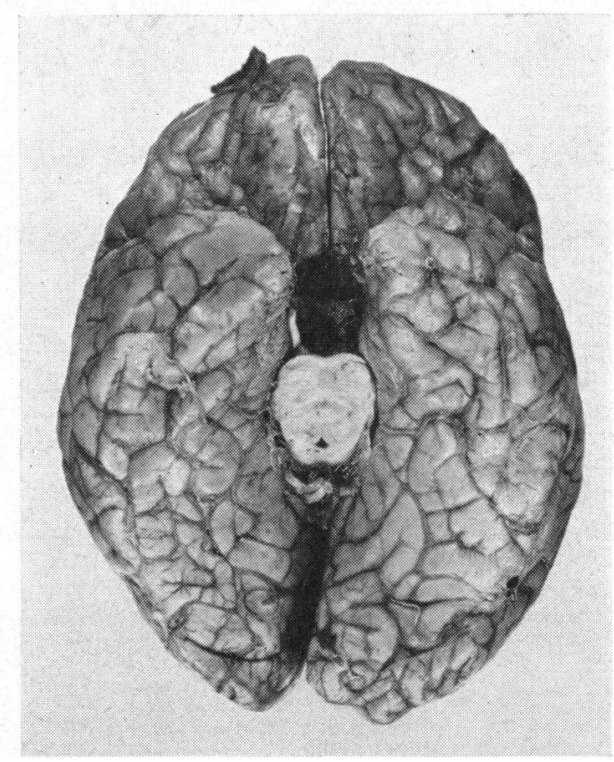

Fig. 6.-Case 2. Basal view of brain showing cavity excavated by the aneurysm.

Comment.-In this case the field defect recorded-a left temporal hemianopia associated with some degree of optic atrophy-pointed to a lesion involving the nasal aspect of the left optic nerve, or the crossing fibres from the left nerve at the anterior angle of the chiasma. It was surprising, therefore, to discover that the aneurysm arose from the right carotid artery, but had extended medially across the midline and had given rise to signs of compression of the contralateral optic nerve.

\section{Summary}

Two cases of cerebral aneurysm are reported which presented with signs of involvement of the visual pathways and without motor defects. Both were unusual in that one presented with sudden blindness on the affected side, while the other appeared with signs of involvement of the contralateral optic nerve. Both patients died after operation and the findings were confirmed by post-mortem examination.

We wish to thank Prof. G. I. Scott and Dr. C. R. S. Jackson for permission to publish these cases. We are indebted to Prof. F. J. Gillingham and Mr. J. F. Shaw, who undertook the neurosurgical care and made their records available, and we are also grateful to Dr. A. A. Donaldson for the neuroradiology, and to Dr. A. Gordon for the pathological reports.

Cullen, J. F. (1964). Brit. J. Ophthal., 48, 590.

\section{REFERENCES}

Dailey, E. J., Holloway, J. A., Murto, R. E., and Schlezinger, N. S. (1964). Arch. Ophthal. (Chicago), $71,463$.

Green, W. R., Hackett, E. R., and Schlezinger, N. S. (1964). I Ibid., 72, 154.

WALSH, F. B. (1964). Ibid., 71, 15. 